\title{
Geographic Disparities in Late-Stage Cancer Diagnosis: Multilevel Factors and Spatial Interactions
}

\author{
Lee R. Mobley, PhD, \\ RTI International Imobley2@nc.rr.com \\ Tzy-Mey (May) Kuo, PhD, \\ UNC-Chapel Hill tkuo@email.unc.edu \\ Lisa Watson, BS, and \\ RTI International lisawatson@nc.rr.com \\ G. Gordon Brown, PhD \\ RTI International ggbrown@rti.org
}

\section{Introduction}

In 2009 in the United States, breast cancer (BC) was the most common cancer in women, and colorectal cancer (CRC) was the third most common cancer in both men and women (Jemal et al. 2009). Among all cancers, both BC and colorectal cancer (CRC) can be detected in early stages through effective screening methods. However, both breast and colorectal cancer screening rates are lower than optimal, resulting in later stage cancers at first diagnosis (ACS, 2011). Currently, $40 \%$ of all BC and $61 \%$ of all CRC in the United States is diagnosed at a nonlocalized stage, which is associated with a lower five-year survival rate (ACS, 2011; Henley et al, 2010; Richardson et al, 2011).

Inadequate $\mathrm{BC}$ screening and access barriers to screening may lead to more advanced stage breast cancer diagnosis and poorer survival (Taplin et al, 2004). Utilization of CRC screening varies by race or ethnicity, education, health insurance coverage, and immigration status. Hispanics, those with less than a high school education, those without health insurance, and immigrants who had been in the US for fewer than 10 years were the least likely to have utilized CRC screening in 2008 (ACS, 2011). Late-stage cancer diagnosis results in higher morbidity and mortality than would obtain with optimal cancer screening utilization. Because these cancers typically occur at older ages, and the population size and life expectancy of older people continues to increase, (Administration on Aging, 2006; Hetzel and Smith, 2001) it is likely that the morbidity and mortality burden from these cancers will continue to increase. Thus, to improve BC and CRC outcomes it is urgent that we develop strategies to identify certain higher-risk locations, so that geographic disparities might be reduced.

\footnotetext{
(c) 2012 Elsevier Ltd. All rights reserved.

Correspondence to: Lee R. Mobley.
}

Publisher's Disclaimer: This is a PDF file of an unedited manuscript that has been accepted for publication. As a service to our customers we are providing this early version of the manuscript. The manuscript will undergo copyediting, typesetting, and review of the resulting proof before it is published in its final citable form. Please note that during the production process errors may be discovered which could affect the content, and all legal disclaimers that apply to the journal pertain. 
In this paper we consider the substantial variation that exists across states in geopolitical variables such as cancer control policies or state insurance regulations. We examine how these interact with other, more locally defined socio-ecological variables to predict the prevalence of late-stage cancer. We find that state environments significantly alter the effect estimates associated with deprivation or social support on breast and colorectal cancer stage at diagnosis. This geopolitical aspect of the cancer control problem contributes significantly to the observed geographic disparities, and has never been studied previously.

Geographic disparities in breast and colorectal cancer prevention and outcomes have existed for decades (Kerner et al, 1988; ACS 2010, 2011; Naishadham et al. 2011). As early as 1988 , Kerner et al. called for using spatial analytic methods to inform targeted neighborhood interventions in comprehensive cancer control (CCC) efforts to increase national cancer screening rates. Since that time, elimination of disparities in cancer screening and outcomes has been a particular focus of CCC efforts (Coughlin et al. 2006). However, despite the identified need for more widespread use of spatial analytic methods to inform place-targeted interventions, at the present time, no materials developed to guide $\mathrm{CCC}$ activities have addressed spatial variation in cancer prevalence, and less than a dozen states include geographic information systems or spatial analysis in their CCC plan activities (CDC, 2006; Given et al., 2005). However, some states have recently begun small-area analyses to identify local areas with higher incidence or late-stage diagnosis of cancers.

The spatial analytic methods employed to date in these small-area analyses have been primarily descriptive. For example, a few states have used various types of spatial statistics or small-area analysis to describe patterns in cancer incidence or late stage diagnoses (Beyer and Rushton, 2009; New Jersey Comprehensive Cancer Control Plan (2008-2012), which cites an earlier study by Roche et al, 2002; and the Komen Foundation (2011)). These studies have provided evidence that spatial patterns vary considerably across geographic scales that are smaller than counties. Such studies are useful for highlighting more specific locations (than counties) where prevalence or incidence rates are higher within states. However, they do not provide information regarding why these patterns may have occurred, based on underlying socioecological factors. Because spatial analytic methods have not been used in predictive analyses that explicate Where, Why, and for Whom we observe these disparities, they persist and result in undue suffering and inefficient use of healthcare resources.

Morever, state-specific analyses are not informative as regards national comprehensive cancer control efforts. The focus on states is an outgrowth of the decentralized approach to cancer control efforts that has been adopted in the US. The methods used in this paper allow for comparisons across states, so that we can begin to see how states compare to one another and where or how a more centralized national comprehensive cancer control policy might direct targeted resources. We use spatial analysis to answer questions related to both Where and Why disparities in late-stage breast and CRC diagnoses are observed. In examining Why, we include person, county, and state level characteristics in a model examining the impacts of these factors. We include state-level variables reflecting characteristics of states' cancer control planning, insurance markets and managed care environments to help model the spatial heterogeneity in observed late-stage cancer incidence from place to place. To answer questions related to Where disparities in late-stage BC and CRC are observed, we generate county level robust predictions of late-stage $\mathrm{BC}$ and $\mathrm{CRC}$ rates from a randomintercept multilevel model. We then use these predicted rates to show the geographic variation in the rates among the cancer populations in the 11 Surveillance, Epidemiology, and End Results (SEER) Registry populations that we study. 


\section{Conceptual Model}

The importance of including several levels of factors in the empirical model is motivated by a conceptual model which addresses two concerns raised in the recent literature. First, Cummins et al (2007) note that recent empirical research focusing on the role of place in shaping health and health inequalities has had a limited focus on isolating the independent contribution of place-level and individual-level factors. They argue that research in place and health should instead recognize the "mutually reinforcing and reciprocal relationships between people and place" (e.g. spatial interaction among people and environments). The notion that interactions between race and place may influence social outcomes is not new (Probst et al., 2004), but other environmental interactions remain largely unexplored (Cummins et al, 2007).

Second, there may be many important dimensions governing the social determinants of disparities, including the broader dimension of regional opportunities, which is largely overlooked in literature to date (Osypuk and Acevedo-Garcia, 2010). Our conceptual model (Figure 1) makes explicit the multiple levels of influence, including the state and larger regional-level factors. While multi-state regimes reflecting regional opportunities are likely to influence cancer outcomes, the 11 SEER Registry populations we study here are geographically disparate and preclude analysis of these fourth-level regional factors.

Figure 1 describes spatial interaction in the United States among people and characteristics of their contextual environments along the pathways to health prevention and subsequent outcomes. This model is a hybrid which merges the behavioral model of utilization (Aday \& Andersen, 1974) with a model of spatial interaction adopted by the World Health Organization (Khan \& Bhardwaj, 1994). Different levels of influence are also present. State factors at the third level are used to reflect the fact that each state in the Unites States oversees a cancer control program that is decentralized in terms of funding and implementation. Also, in the United States, state health care environments are heterogeneous, governed by local and regional politics, state-specific health insurance regulation and mandates, social systems, market-level forces that determine supply factors, and community- level forces that determine social factors. Individuals exhibit predisposing, enabling, and need characteristics, all of which interact with the forces in the broader system. The factors that existed at the time and in the place of initial cancer diagnosis are most relevant for our research questions.

As noted in the literature, when cancer screening rates are lower, incidence of late-stage cancers at first diagnosis will be more common. However, the empirical relationship is confounded by the fact that higher screening rates increase probability of detection and the observed number of cancers and late-stage cancers, relative to their true incidence, which is unobserved. Thus when explaining late-stage cancer incidence rates in small areas, it is important to control statistically for utilization of cancer screening among the population. Cancer prevention (screening) is governed by the same factors as cancer outcomes (observed cancer stage or mortality) but screening may occur along the pathway to outcomes. Thus cancer screening is an important control factor to include in the modeling of the final outcome, cancer stage at first diagnosis. In Figure 1, utilization of screening is along the pathway but not necessarily encountered by all persons, reflected in the wide arrow connecting the socioecological system and outcomes.

We are particularly interested in an understudied area: how the state-level variation in health insurance environments (Level 3) is predictive of cancer outcomes. Health insurance mandates are controversial but numerous, including services mandates (e.g., alcohol treatment), provider mandates (e.g., chiropractors) and coverage mandates (e.g. BC 
screening or inpatient stay following mastectomy). For example, all states except one (Utah, during the time interval we study) mandated that health insurance cover BC screening (NCSL, 2011). Health insurance regulatory environments vary considerably across states, and several studies have examined the impacts of insurance regulation and mandates on insurance premiums and rates of uninsured individuals (CBO, 2005; Kowalski et al., 2008; LaPierre et al., 2009; New, 2006). One study concluded that opening up competition among plans across states would lower premiums and increase value in the benefits packages offered to consumers (Parente et al., 2008).

No published studies concerning population cancer outcomes have included state-level factors or examined state-level variation in health insurance market or health policy factors and their impacts on cancer prevention and outcomes. Our theory is that because health insurance regulation and mandates impact information to consumers and perceptions of the need for certain screening tests, prices (premiums), free choice of providers, and plan coverage, they have downstream impacts on preventive care behaviors, satisfaction with providers, treatments received and quality of care. This health economics area of research has been ignored in the literature on cancer prevention and outcomes, and is a unique contribution from this paper. This research is critically important as our nation grapples with healthcare reforms and searches for those most efficacious in allocating limited resources (Weil and Tallon, 2008).

\section{Methods}

\section{Study Sample}

We used data describing the SEER Registry populations in the 11 states covered (CA, CT, IA, KY, LA, NJ, NM, and UT) or partially covered (GA, MI, WA) by the Registries at the time of our study. The study population includes persons of all ages diagnosed with $\mathrm{BC}$ or CRC between 2000 and 2005 who were eligible for any form of Medicare or Medicaid insurance. Medicare covers the vast majority of persons aged 65+, and other younger individuals who have disabilities or end-stage renal disease, while Medicaid covers lowincome individuals and in some states helps elderly persons pay for their Medicare insurance. According to the SEER-Medicare documentation, $94 \%$ of persons aged $65+$ are linked to Medicare enrollment files. Thus, the study sample includes virtually the entire population of persons aged 65+ with known cancers in these SEER Regions. The study population does include individuals younger than age 65, but only those who were entitled through low income, disability, or End-Stage Renal Disease (ESRD) to receive Medicare or Medicaid benefits. Thus the study sample is not representative of the under age 65 population with cancer, but it is quite representative of those aged 65+ who have cancer in these SEER regions. However, because BC and CRC cancer incidence rates are much higher for persons aged 65+ (Howlader et al, 2011), the sample is quite representative of persons with cancer in these SEER regions. For CRC, the age-adjusted incidence rates ${ }^{i}$ for new cases per 100,000 persons are much lower for persons under age 65 (11.5) than for persons and aged 65+ (188.9); for BC these are 23.2 and 84.2, respectively. Because incidence rates for breast and colorectal cancers increase with age, we would also expect that rates of late-stage diagnosis for these cancers would increase with age.

In some states (GA, MI, WA) the SEER Registries did not include residents from all over the state at the time of our study. The Georgia population includes the urban Atlanta metropolitan area and some selected rural counties, while the Michigan population includes metropolitan Detroit, and Washington includes both some urban and rural areas. Thus the

$\mathrm{i}_{\text {Incidence rate }}=($ New cancers $/$ Population $) \times 100,000$ 
study population is quite representative of persons aged 65+ in eight states ( CA, CT, UT, LA, IA, KY, NJ, NM) but representative only of subpopulations of persons aged $65+$ in the remaining three states (GA, MI, WA).

For people who had multiple cancer diagnoses, we selected only those whose first diagnosis was either BC or CRC and whose cancer was staged at time of diagnosis. The sample included 116,121 women with BC and 106,224 men and women with CRC as their primary cancer diagnosis and recorded stage at diagnosis. At the time of their first cancer diagnosis during 2000-2005, these people resided in the SEER Registry areas of the 11 states we study. The address at time of cancer diagnosis was used to assign state and county contextual variables.

\section{Data Sources}

The SEER Registries provide rich information for the population with cancer diagnoses, including month and year of cancer diagnosis, cancer site, histological type, cancer stage information (including 'unstaged'), county of residence at time of primary cancer diagnosis, mortality status, and patient demographics. County data linked to persons in the multilevel modeling come from an extensive online geospatial database (http://rtispatialdata.rti.org). State insurance data come from the National Coalition of State Legislatures (NCSL, 2011). ${ }^{\text {ii }}$ The Comprehensive Cancer Control (CCC) plan inception year data were obtained from Comprehensive Cancer Control Plans: A Content Review (CDC, 2005). InterStudy was the source for county-level managed care insurance plan penetration.

\section{Measures}

Person-level variables-The information on cancer stage is from SEER Summary Stage 2000, which we defined for the analysis as a dichotomous outcome variable: late-stage versus early-stage. Late-stage included regional and distant stage, whereas the early-stage includes the in-situ and localized diagnosis. Cases with unstaged cancers were dropped, consistent with other geographic studies of late-stage cancer incidence (McLafferty and Wang, 2009; Meliker et al, 2009; Wange et al, 2008). In our data, rates of late-stage BC range from a low of about $26 \%$ in Connecticut to a high of about $33 \%$ in Louisiana. Rates of late-stage CRC range from a low of about $49 \%$ in Utah to a high of about $58 \%$ in Washington state (Table 1).

We used the SEER-Medicare linked data, which provides demographic information including type of health insurance (Medicare traditional fee-for-service (FFS), dual eligibility for Medicare/Medicaid, Medicare managed care plan ${ }^{\text {iii }}$ ) and includes all persons, regardless of age, who have some sort of Medicare or Medicaid coverage or eligibility. Demographic information on subjects included age, race or ethnicity, marital status, original reason for Medicare entitlement, and an indicator of whether the state provided special

\footnotetext{
${ }^{i i}$ See: National Conference of State Legislatures (NCSL), (May 2011). "Managed Care State Laws and Regulations, Including Consumer and Provider Protections", available online November 2011: , http://www.ncsl.org/default.aspx?tabid=14320

This summary compilation of state laws and polices was originally published 2000, with regular updates and additions through 2005. Because states enacted far fewer changes in this area since 2005, this report is no longer maintained on a regular basis. It remains an accurate historical view of the range of state-specific initiatives in an era where there was relatively little federal law. The 2010 Affordable Care Act, which is a federal law, substantially adds to the regulatory requirements in some of the areas covered in this report. See NCSL's latest (2010-2011) reports and descriptions online at the NCSL Health Reform website, http://www.ncsl.org/ Default.aspx?TabID=160\&tabs=831,139,1156\#1156.

iii Medicare traditional FFS insurance allows beneficiaries to utilize any provider or hospital that is willing to serve them, while Medicare managed care plans require beneficiaries to go to preferred providers and facilities associated with the plans, which are offered by private insurance companies who are reimbursed by Medicare. Seniors have choice over these two types of coverage in an annual insurance enrollment period. Medicaid is health insurance coverage for certain low income people or disabled individuals, offered separately by states with various eligibility requirements. People covered by both Medicare and Medicaid are considered 'dually eligible'.
} 
financial assistance. People receiving special assistance are generally low income, disabled, or have end-stage renal disease (ESRD) and are called 'dually eligible' (for both Medicare and Medicaid) (MEDPAC, 2004). This group is defined as our 'vulnerable' cancer subpopulation. Marital status and dual eligibility indicators were defined in the year of cancer diagnosis.

Table 1 provides sample statistics, by state, including the number of persons included in the Registry sample, the number of counties in the state with registry population residences, and proportions of demographic variables for each state's registry population. We define and use three racial or ethnic groups (whites, Blacks, and all others). The aggregation across races and ethnicities in the 'others' category (which also includes persons of unknown race) was unfortunately necessary due to small numbers of sample members of certain races or ethnicities in some counties and states. This is an empirical constraint imposed by these data; in particular, there were too few persons of Hispanic origin in each and every state to break this category out. An earlier paper by Kuo, Mobley, and Anselin (2011) looking only at California women with late-stage $\mathrm{BC}$ was able to break out Hispanic women as a separate group, because group subpopulations in this state were large enough to confer the statistical power necessary to differentiate among them and whites. However another paper examining late-stage cancers among seniors across the SEER Registry areas was not able to break this group out both by state and ethnicity, and pooled data across all states in order to examine minority status effects (Haas et al, 2008). Because we include three levels in the multilevel model used in this paper, having such sparse cells in some states caused failure to converge. Our main interest is in the insurance market interaction effects, which necessitates keeping states as separate entities in the modeling, thus we cannot provide finer racial or ethnic group breakouts than the three groups (white, Black, all others).

About $40 \%$ of the cases studied were residents of California, with New Jersey providing the next largest group. Three states - GA, MI, and WA - are only partially covered by the SEER registries so their cancer patients don't represent their entire states. California, Louisiana, and Kentucky show the highest proportions of vulnerable, dually eligible cancer patients.

Geographic Risk Factors-In specifying the empirical models parsimony was essential, otherwise the models would not be estimable. We first looked at simple correlations among many possible variables, and thought about hypothetical relationships and interactions based on the literature. The final models are parsimonious but reflect key elements from Figure 1, the conceptual model. The average distance to closest provider of endoscopy or mammography services in the county is included for each person in our empirical model, reflecting the density of providers in their county. The source of the distance measure is the freely available RTI Spatial Impact Factor Database (https://rtispatialdata.rti.org). As documented in the database metadata, this county-specific measure is the unweighted average distance (miles) over all ZIP codes with centroid in the county to closest provider ZIP code centroid. The measure was calculated each year 2001-2006 using provider address ZIP codes from $100 \%$ of physician carrier claims for Medicare patients' utilization these services. We assume that this average distance measure reflects the availability of these providers and services to the entire population in an area. This variable is thus a direct measure of the potential interaction between people and their healthcare environments, indicated by the horizontal arrow across the figure. Other variables defined at the county and state levels correspond to other portions of Figure 1.

Table 2 summarizes the county-level variables included in the modeling, by state, with sources. There is considerable variability in these county-level variables across the 11 states. These include the proportion of the population enrolled in HMOs, the proportion of the 
cancer population that are vulnerable (dually eligible or have disability or ESRD), the proportion of Medicare FFS enrollees who used BC or CRC screening in 2001, the proportion of persons aged $80+$, and a residential segregation index. The segregation index, defined at the county level, is matched to a person's race or ethnicity in the modeling. This variable (like distance to closest provider) is thus defined from the person's perspective and is another measure of the direct interaction between people and their environments, captured by the horizontal arrow in the figure.

The residential segregation measure we use, the isolation index, was defined by Massey and Denton (1988). We obtained the measures from the RTI Spatial Impact Factor Database, which includes all 5 dimensions of residential segregation as defined by Massey and Denton, and at various spatial scales. This isolation index was calculated separately using 2000 Census of Populations data for Blacks, Asians, Hispanics, Pacific Islanders and Native Americans, and all other races combined. Following Massey and Denton's approach, each race or ethnicity's isolation index was defined relative to whites. We chose a measure from the RTI database defined at the county level, which has values ranging from 0 to 1 and where higher values represent greater isolation or segregation of minorities from whites (Massey and Denton, 1988). Higher values represent higher probability that minorities live among people of their same race or ethnicity; lower values represent more mixed communities.

Massey and Denton's isolation, clustering, and dissimilarity indices have been used rather extensively in social sciences research. Kramer and Hogue (2009) reviewed 39 studies of ecological factors and social outcomes, and found that only two studies used a spatial clustering measure, whereas eleven studies used an isolation index and twelve stuudies used a dissimilarity index. The clustering index is more useful in studies of urban areas than in studies (such as our own) spanning the urban-rural continuum.

To make our findings comparable with recent literature on late-stage cancer incidence (Kuo, Mobley, and Anselin 2011; Dai, 2010; Haas et al, 2008), and cancer screening behavior (Mobley et al, 2008a, 2008b, 2009), we chose to use the isolation index, which has been interpreted as enhancing social cohesion or support when defined at the neighborhood level. Several studies posit that conversely, residential isolation reflects an adverse environment (Dai, 2010), but others posit that this can be modified positively by a high degree of clustering into enclaves which enhances political empowerment (Bell et al, 2006; Laveist, 1992; 1993). This political empowerment interpretation may be valid for the isolation index defined at the larger geopolitical unit (county) rather than in smaller areas, because a larger index at a larger scale indicates a greater degree of spatial clustering. That is, the county may reflect broader factors (than social support) such as political influence held by minorities in the geopolitical units. One paper looking at the association between isolation and breast cancer screening, where isolation was measured at successfully larger geographic levels, concluded that level of aggregation does matter and that different levels may reflect different ecological forces (Mobley et al, 2008a). Because we use county-level isolation measures, we expect that these will reflect political influence held by minorities as a broader manifestation of social cohesion and support.

Managed care health plan penetration is another important geographic risk factor. Managed care plans are designed to promote preventive healthcare and case management so as to improve allocation of resources. Early managed care plans provided more comprehensive coverage of preventive care services, such as cancer screening, and the lower out-of-pocket costs for these services encouraged their utilization relative to enrollees in traditional plans (Luft, 1980; Wolinsky, 1980; Sullivan, 1999). Historical evidence suggests that enrollees in Medicare managed care plans exhibited lower incidence of late-stage diagnoses for both 
breast and colorectal cancers than their peers enrolled in traditional FFS Medicare (Riley et al, 1994, 1999; Roetzheim et al, 2008). More recently, however, the Government Accountability Office found no difference in the utilization of cancer screening among Medicare beneficiaries enrolled in Medicare managed care plans versus traditional FFS plans (GAO, 2012). In these sorts of comparisons, it is essential to control for selection bias among participants in the two plan types. In our own analysis which accounted for participant characteristics known to be associated with selection bias, and modeled the geographic variability across the different state health markets in the United States, we found that managed care increased utilization of breast and colorectal cancer screening in some markets, but not in others - so the evidence is mixed (Mobley et al, 2008b; Mobley et al, 2010; Mobley et al, 2011). This is not surprising because states have varied insurance regulations and these would be expected to have differential impacts of healthcare utilization and outcomes, which is the basic tenet of this paper.

Managed care plans have had quite varied success at penetrating different regions of the country, moreso in urban than in rural areas (Mobley and Frech, 2007). Managed care plans have been shown to change the way that medicine is practiced in some highly penetrated markets, a phenomenon that is described as 'managed care market spillovers' by economists (Baker, 2003; Miller and Luft, 1994; Mobley et al, 2011). Spillover effects from managed care have been variously defined as changes in practice patterns, costs, or the diffusion of new technology relative to what might occur in markets with little managed care penetration. Changes in practice patterns can spill over to people who are not insured by the managed care plans but who are seen by the physicians who are affected by the information the plans disseminate. Also, people may compare treatment options with and be influenced by the care patterns received by their peers who are in managed care plans. In this way managed care plans can impact the way medicine is practiced in their markets, impacting adherence to screening guidelines and early detection of cancers by market participants, whether or not they are enrolled in managed care plans. We expect a positive impact of managed care penetration on cancer screening among our study population, resulting in a negative association between managed care penetration and late stage of cancer at first diagnosis, because screening promotes earlier detection of cancer.

We chose six state insurance laws or mandates to examine in the context of incidence of late-stage cancer, as summarized in Table 3. Many laws and mandates passed during this period were aimed at controlling managed care plan practices that restricted consumer choice, among other things (NCSL, 2011) during a period of broad backlash against managed care (Mobley and Frech, 2007). Among dozens of laws and mandates, we restricted our focus to those which had a plausible hypothesized relationship with BC or CRC stage at diagnosis and also exhibited variation across the 11 states. Another state-level factor included in the models is the time elapsed since 1998 (in years) before a comprehensive cancer control (CCC) plan was developed for the state, which varies across states from 0 to 6 years. States with a later adoption of CCC plans are expected to have lower impacts from those efforts, manifesting as lower cancer screening rates and higher rates of late stage diagnosis.

Hypothesized Relationships-We investigate how state-level health economic environments impact cancer outcomes through cross-level interactions with communitylevel factors that are specified from the perspective of the cancer patients in those communities. A recent paper predicting rates of late-stage BC diagnosis in California (Kuo, Mobley, and Anselin, 2011) argued the importance of using 'relevant contexts' for people making health care decisions, and found that women of different race or ethnicity living in the same places faced different environments. These 'relevant contexts' are reflected in the 
horizontal arrow across Figure 1, which illustrates the spatial interaction between people and their environments.

There are differences in the dynamics of breast and colorectal cancer screening factors which impact outcomes and lead to different model specifications for BC and CRC. During our study period, everywhere but Utah, most insurance fully covered mammography, or there was at most a small copayment. For CRC screening by endoscopy (colonoscopy or sigmoidoscopy) procedure costs and copayments were much higher. There are also significant time costs involved in preparing for endoscopy, and a partner is needed for transportation. There are also non-trivial risks associated with endoscopy which increase with age, frailty and disease comorbidity, and these population demand factors influence the diffusion and availability of these services (Mobley et al, 2011). To undergo preventive CRC screening, the patient must come to the conclusion that the benefits exceed the costs and risks, which may not happen without encouragement by healthcare providers and evidence of provider safety (reputation). Having an established provider relationship is expected to enhance continuity of care and to reinforce the importance of timely screening.

We expect that lower-income individuals, many of whom could be of minority status, will be much less likely to utilize preventive CRC screening, and thus be more likely to present at advanced stage at first diagnosis of cancer. Lower-income and minority elderly individuals were more likely to enroll in Medicare managed care plans during this period because Medicare managed care plans actively sought enrollees among minorities, targeting their recruitment activities to poorer urban communities (AHIP, 2005; Atherly and Thorpe, 2005). This is important here because many of the insurance regulations and mandates were enacted to protect consumers from stringent managed care insurance practices that reportedly led to adverse outcomes (NCSL, 2011). We hypothesize that those states with insurance laws and mandates that encourage quality competition among managed care plans (plan report cards) or mandate that managed care plans provide good continuity of care will benefit their vulnerable, low-income cancer populations. Even when these populations are not enrolled in managed care plans, we expect that managed care spillovers will be important geographic risk factors, as noted above.

$\mathrm{H}_{1}$ : In states with either mandated report cards or continuity of care laws, communities of vulnerable populations will exhibit lower late-stage $\mathrm{CRC}$ rates than their counterparts in states without these mandates.

$\mathrm{BC}$ screening does not impose the same financial and non-financial barriers to utilization as does CRC. Instead, social forces may be more important determinants of preventive care, such as BC screening, and downstream incidence of cancer stage at diagnosis. We focus on the probable impacts of residential isolation, which has been found important in recent studies of BC screening and stage at diagnosis (Kuo, Mobley, and Anselin 2011; Haas et al, 2008; Mobley et al, 2008a, 2008b, 2009). We expect that women who live among people of their same race or ethnicity have better geopolitical cohesion or social support, and may be better informed about the importance of BC screening, or better motivated to utilize it, resulting in lower probability of late-stage BC diagnosis. Also, a woman's information or motivation may be enhanced by choosing her own doctor or having direct access to an OB/ GYN as a primary care provider. In addition, having the option for inpatient hospitalization after mastectomy may reduce the fear of finding one has late-stage cancer, spurring utilization of mammography.

$\mathrm{H}_{2}$ : In states with either mandated inpatient hospitalization after mastectomy, any willing provider laws, freedom of choice laws, or direct access to OB/GYN, women with BC living is more segregated communities will exhibit lower latestage diagnosis rates than their peers in states without these mandates. 
Statistical Analysis-We estimated multilevel logistic models using data from person, county, and state levels by pooling the data across the eleven states. We used the Generalized Linear Latent and Mixed Model (Gllamm) procedure (Rabe-Hesketh et al, 2004) in Stata (StataCorp, 2011) to fit random intercept models that allow both county and state intercepts to vary. Because the response is dichotomous (yes or no for late stage cancer diagnosis), we chose the logit link to model the response variable. In addition, we used the adaptive quadrature integration option in Stata to obtain more accurate estimates (RabeHesketh and Skrondal, 2008). Because we hypothesize that the factors which impact the incidence of late stage $\mathrm{BC}$ diagnosis may not be the same as those impacting CRC diagnosis, we specify and estimate the $\mathrm{BC}$ and $\mathrm{CRC}$ models separately.

To reduce collinearity, we examined only one cross-level interaction between the county and state variable(s) per model. For the CRC models, we included a cross-level interaction between the county-level proportion of cancer population who were vulnerable (dually eligible, diasabled, or with ESRD) and each state-level insurance mandate listed in $\mathrm{H}_{1}$. The estimation results for CRC models are included in Table 4. For the BC models, with estimates presented Table 5, we included a cross-level interaction between the county-level isolation index of residential segregation, aggregated to county level from separate indices matched to each woman's race or ethnicity, and each state-level insurance mandate listed in $\mathrm{H}_{2}$. A simplified, representative equation for both the BC and CRC models is:

$$
\mathrm{Y}_{\mathrm{ijk}}=\gamma_{00}+\gamma_{1} \mathrm{X}_{\mathrm{i}}+\gamma_{2} \quad \mathrm{C}_{\mathrm{j}}+\gamma_{3} \quad \mathrm{~S}_{\mathrm{k}}+\gamma_{4} \quad \mathrm{~S}_{\mathrm{k}}{ }^{*} \mathrm{C}_{\mathrm{j}}+\mu_{0 \mathrm{j}}+\mu_{0 \mathrm{k}}+e_{\mathrm{ijk}}
$$

Where $\mathrm{Y}_{\mathrm{ijk}}$ is $\log$ of the late-stage probability divided by early-stage probability for person $\mathrm{i}$ in county $\mathrm{j}$ and state $\mathrm{k}, \gamma_{00}$ is the overall intercept term for the 3-level model, $\mathrm{X}_{\mathrm{i}}$ represents all personal level factors, $C_{j}$ represents the contextual factors characterizing county areas $j$, $\mathrm{S}_{\mathrm{k}}$ represents the binary indicators characterizing state insurance environments and the CCC plan implementation variable, $e_{\mathrm{ijk}}$ is the residual of the outcome variable $Y_{\mathrm{ijk}}$, and $\mu_{0 \mathrm{j}}$ and $\mu_{0 \mathrm{k}}$ are the unique random intercepts for the county and state levels in the model. The residual $e_{\mathrm{ijk}}$ reflects within-county variation among cancer patients, including measurement error and variation among people that is not explained by the model. The county and state intercept terms are themselves random, with associated error terms $\eta_{j}$ and $\eta_{k}$, which reflect variation between counties and states, beyond what is explained by the model. The variances of the three error terms are estimated among other parameters from the data.

As discussed in Gelman and Hill (2007, p 247), when there is very little county level variation, the multilevel model reduces to a classic regression model with no group-level indicators (complete pooling, ignores variation between counties). On the other extreme, when the group-level coefficients vary greatly relative to their standard errors, the multilevel model reduces to classic regression with group indicator variables (sometimes known as fixed effects models, or the no-pooling model). In intermediate cases, the complete pooling model ignores variation between counties, while the no-pooling/fixed effects model overstates this variability, by overfitting the data in each county and making the individual counties seem more different from one another than they actually are (Gelman and Hill, 2007, p 253). The multilevel model estimates are a compromise, producing area-level intercepts that are a weighted average from results that would obtain under completepooling and no-pooling models. This weighted average reflects both the relative amount of information available for individual counties (county sample sizes) and the relative amount of information available for the average of all the counties (number of counties). In the weighted averages from samples where counties have less information (smaller samples), the weighting pulls the county-level estimate closer to the state average. In the weighted averages from samples where counties have lots of information (large samples), the 
corresponding county-level estimates are closer to the county averages. In intermediate cases, the multilevel estimates lie between the two extremes and are thus more robust than estimates produced by either complete pooling or non-pooling models. Thus, the multilevel modeling approach used here accounts explicitly for the size of populations in counties, and stabilizes the variance for those counties with small populations, producing robust countylevel estimates (Gelman and Hill, 2007). More specifically, in situations where the variance estimate for area-level effects (i.e. variance of the $\mu_{0 \mathrm{j}}$ and $\mu_{0 \mathrm{k}}$ parameters) is small, using a multilevel approach is most important because it allows intercept estimates to vary by group yet estimates them more precisely (i.e. with lower variance as compared to ordinary regression), especially for groups with small sample size. The intercept estimates are then used with the fitted model to produce the county-level estimates.

There are other advantages from multilevel modeling. In fixed effects models, it is not possible to include both group indicators and group characteristics. A multilevel model is a compromise between these two extremes, with several advantages. A major advantage of multilevel models is the ability to estimate a separate intercept for each place and also include place-specific covariates in the same model. An additional advantage is the ability to then interact the area-level covariates with the person-level covariates, to determine crosslevel interaction effects. Assuming a random distribution for the group-level intercepts reduces the number of parameters estimated (relative to fixed effects) and the increased parsimony of the model allows for greater flexibility in examining these higher-order effects and their interactions. Another advantage of the multilevel model is that we can get reasonable predictions for counties with small sample sizes, which would be difficult using classic regression.

Another advantage of using the random-intercepts multilevel model is its utility in accounting for selection (migration) of people into areas. For example, when there are no omitted area-level effects and when people are randomly assigned to areas, any variation in health outcomes between areas could be attributed to the areas themselves (Oakes, 2004, p. 1934). However, people are not randomly assigned to areas. People self-select their locations so it is important to include compositional variables reflecting characteristics of the study population, such as age, marital status, comorbidity, and socioeconomic status. When these variables determine the selection behavior, then including them in the multilevel model adjusts the predicted person-level outcomes (used to construct area-level rates) for differences in neighborhood composition due to selection. Because the observed differences in health outcomes between areas cannot be separated from the selection or biological information of people residing there, including compositional variables as controls is essential (Oakes, 2004: pp 1938-1939). The predicted area-level estimates of rates of latestage diagnosis from random effects models with both compositional and contextual factors are thus particularly useful for reliably predicting areas with highest and lowest late-stage cancer rates.

Results-Four models with statistically significant cross-level interaction effects are reported here. Two significant models for CRC and two significant models for BC are presented in Tables 4 and 5. Goodness of fit statistics (AIC) are nearly identical across the CRC models (Table 4) and the BC models (Table 5). The tables present coefficient estimates, which can be readily converted to odds ratios using exponentiation.

Using the CRC model results, the coefficient of $\gamma 2$ is the mean effect of living in a more vulnerable community (i.e. those counties with higher rates of dual eligibility, disability, or ESRD among cancer patients), $\gamma 3$ is the mean effect of regulation requiring the state insurance mandate, and the coefficient estimate $\gamma 4$ is the change in the effect of living in a more vulnerable cancer community across states with and without the law (specified in the 
table columns). Living in a more vulnerable community $(\gamma 2)$ is associated with significantly higher rates of late-stage CRC in both models. However, states with continuity of care or provider report card laws had significantly lower rates of late-stage CRC among their most vulnerable cancer communities. (The coefficient estimates $\gamma 4$ for these interaction effects from the continuity of care or provider report card laws models are -0.961 and -0.976 , respectively). This suggests that these laws protected the most vulnerable cancer patients by improving information or the ability to maintain provider relationships and continuity of care.

Using the BC model results, the coefficient of $\gamma 2$ is the mean effect of women living in more segregated community, $\gamma 3$ is the mean effect of regulation requiring the state insurance mandate, and the coefficient estimate $\gamma 4$ is the change in the effect of living in a more segregated community across states with the law relative to those without the law. Living in a more segregated community $(\gamma 2)$ is negatively associated with late-stage BC rates, suggesting a protective effect, but this is only statistically significant in the inpatient stay law model. The interaction effects $(\gamma 4)$ reflecting states with mandated allowance for inpatient hospitalizatioon following mastectomy or any willing provider laws had positive associations, suggesting higher rates of late-stage $\mathrm{BC}$ among the most residentially segregated cancer communities (i.e. those counties with higher indices of residential isolation among women with cancer). This suggests that living in more segregated communities, among women of same race or ethnicity as self, exhibited worse outcomes in the states with these laws. States that enacted both laws include CT, GA, KY, and NJ, while states enacting the inpatient stay law only were CA and NM (Table 3). This is puzzling, but may reflect the fact that in cross-sectional studies, direction of causality cannot be ascertained. These laws may have been enacted in some states with higher geopolitical influence from highly segregated communities (including whites), because rates of late-stage cancer and other adverse disease outcomes were so high.

To conduct the more complex assessment of net effects associated with state-level insurance variables requires a combination of estimates evaluated at the means of the county-level variable included in the interaction. ${ }^{\text {iv }}$ As regards the continuity of care law, we find both positive and negative net effects among the seven states that enacted this law, as compared to states without this law (null effect). The three states with largest vulnerable population proportions had negative (protective) net effects: CA (-0.02), KY (-0.04), and LA (-0.06); those with smaller vulnerable population proportions had positive (not protective) net effects (IA, MI, NJ, WA). However, nine states with report card laws saw consistently positive (not protective) net effects, reflecting higher rates of late-stage CRC than states without this law (with net effects ranging from about 0.07 to 0.22 ). Thus the continuity of care law seemed to offer protective effects to vulnerable populations in some states, but provider report card laws did not. For BC, four (of six) states mandating allowing inpatient care after mastectomy saw negative net effects (lower rates of late-stage BC) than states without this law, ranging from -0.02 to -0.08 . Thus the inpatient stay law seemed to offer protective effects to women in segregated communities in the four more racially mixed states among the seven that had passed this law (CA, GA, NJ, NM -versus CT and KY). However, in the second $\mathrm{BC}$ model, four (of four) states mandating any willing provider saw positive (not protective) net effects, compared to states without this law, ranging from 0.13 to 0.16 .

These CRC and BC model results suggest that state insurance laws do have significant associations with late-stage cancer incidence, among the 11 state Registry populations studied. The estimated coefficients must be interpreted cautiously, however, as statistical

\footnotetext{
${ }^{i v}$ Derivation of these net effects from the state insurance variables is calculated as follows. Model: $Y_{i j k}=\gamma_{00}+\gamma_{1} X_{i}+\gamma_{2} C_{j}+\gamma_{3}$ $\mathrm{S}_{\mathrm{k}}+\gamma_{4} \mathrm{~S}_{\mathrm{k}} * \mathrm{C}_{\mathrm{j}}+\mu_{0 \mathrm{j}}+\mu_{0 \mathrm{k}}+e_{\mathrm{ijk}} \mathrm{d} \mathrm{Y}_{\mathrm{ijk}} / \mathrm{d} \mathrm{S}_{\mathrm{k}}$, when $\mathrm{S}_{\mathrm{k}}=1,=\gamma 3+\gamma 4^{*}\left(\right.$ mean $\left._{\mathrm{j}}\right)$; when $\mathrm{S}_{\mathrm{k}}=0,=0$
} 
associations (rather than as causal factors) because our data are cross-sectional. However, as described above, the model results can be used to robustly generate predicted late-stage rates for counties, and provide information regarding which are the highest and lowest risk places among counties in multiple states.

\section{Spatial Translation of Findings from Spatial Analysis}

We used results from the CRC model with continuity of care law, and the BC model with inpatient stay following mastectomy law, to construct confidence intervals for each county's predicted late-stage cancer rate, using a delete-1 Jacknife method. ${ }^{\mathrm{V}}$ Next, we sorted the county-level predictions from lowest to highest value, and identified the lower and upper quartiles from this distribution. Using the confidence intervals, we determined that the counties in the lower quartile of the distribution had late-stage rates that were not overlapping with those in the upper quartile of the distribution, suggesting a significant difference between the counties in the upper and lower quartile groups $(\mathrm{p}<0.05)$.

In the graphics which follow, counties in the lower quartile (Q1) and in the highest quartile (Q4) are shown from both the BC and CRC models together. A bivariate map is used to display these two sets of predictions jointly, in Figures 2 and 3, below. The map legend is a $3 \times 3$ color grid that shows all combinations of Q1, Q4, or Q2-Q3 county designations, for all counties and both cancer types. The counties colored black, bright red, bright blue, and white (the four corners of the bivariate legend) are of most interest. Counties colored white

\footnotetext{
${ }^{{ }}$We ultimately want to use confidence intervals to assess whether particular counties have predicted values that are significantly lower or higher than other counties. In order to obtain confidence intervals for the model's predicted county level probability of latestage disease at first cancer diagnosis, we used the delete-1 Jackknife method (Wolter 2007). The delete-1 Jackknife method provides an efficient way to obtain reference samples and uses a replication procedure on these samples to derive distributions for particular estimates of interest. The reference samples are the $n$ combinations of different groups of counties that are possible when sequentially dropping one from a group of $\mathrm{n}$ counties and using the remainder as a subsample (with sequential replacement).

The computation algorithm for the delete-1 Jackknife method is as follows. Each county is sequentially removed from the full data set. This will produce $\mathrm{n}$ replicates (subsamples). For each of these subsamples, we estimate a multilevel model using a SAS GLIMMIX procedure, allowing intercepts for both states and counties to be random. From each subsample model's output, we use the estimates of the fixed effects and random intercepts to compute the county level predicted values, aggregated from the person-level predicted values. Because the dependent variable is dichotomous (whether or not a person has late-stage disease at first cancer diagnosis), we used the logit transformation to obtain the predicted probability of late-stage diagnosis for each county.

Finally, we used the set of $\mathrm{n}$ predicted values of late-stage diagnosis for each county to compute the Jackknife variance using the following formula (Wolter 2007):
}

$$
\operatorname{Var}(\widehat{p})=\frac{n-1}{n} \sum_{t}^{n}\left(p_{t}-\widehat{\rho}\right)^{2}
$$

where $p_{i}$ is the predicted value for county i from each of the $\mathrm{n}$ subsamples, $\hat{p}$ is the average of the $p_{i}$ for county i from all the subsamples, and $\mathrm{n}$ is the number of counties in the entire sample.

After we obtain the Jackknife variance, we compute the confidence intervals for each county's predicted rate of late stage cancer diagnosis using the following formula:

$$
\widehat{p} \pm t_{\left(1-\frac{2}{\alpha}, n-1\right)} * \sqrt{\operatorname{Var}(\widehat{p})}
$$

where $\alpha$ is the desired level of statistical significance. We use $\alpha / 2=0.025$ to construct the two-tailed, $95 \%$ confidence interval for each county's predicted rate.

The software packages that we had available to fit the models (SAS or STATA) do not appear to have the capability to produce the desired variance estimates, or the set of variance-covariance matrices necessary for constructing them. We used the delete-1 jackknife method instead of other options (such as bootstrapping) due to its ease of implementation (using SAS Programming) and our ability to account for known sources of variances. That is, this replication method accounts for the random selection of counties and potential intra-county correlation of person-level observations. A limitation is that the delete-1 jackknife method employed here only considers between county variance, and does not directly account for between state variance, which may be producing a biased estimate. 
have predicted rates of late stage BC and CRC (both) in the lower quartile (Q1) of the distribution across all counties in the 11 states. On the other extreme, counties colored black have predicted late-stage cancer rates for both cancer types that are in the upper quartile (Q4) of the distribution. The bright red color indicates that $\mathrm{BC}$ rates are in the lower quartile while CRC rates are in the upper quartile, while the bright blue color indicates that $\mathrm{BC}$ rates are in the upper quartile while CRC rates are in the lower quartile. Generally, the red colors signal concerns for CRC while the blue colors signal concerns for BC. Results suggest that states like California and Connecticut and Iowa (with lots of red and little blue) should focus their CCC efforts more so on CRC prevention, while New Jersey (all blue) should focus $\mathrm{CCC}$ efforts on BC prevention. Six other states show one or more counties colored black, suggesting that there is concern regarding high late-stage rates for both cancers.

Spatial translation of findings from spatial analysis at multiple levels that allows comparisons across states is a logical first step towards designing national intervention strategies using targeted resources. While the county (our smallest unit of analysis) may be so large that it masks spatial patterns within it, our broader scale multilevel analysis allows direct comparisons across states. The following provides a specific example of why this is useful for national policy. While the geographically specific concentrations of late-stage breast cancers identified at sub-county locales in Connecticut are certainly important for local CCC efforts, small-area analysis of Connecticut alone masks the fact that late-stage BC rates in Connecticut are actually in the lowest quartile among the 11 states with SEER Registries. Late-stage CRC is more of a concern for Connecticut, from a national perspective (Figure 3). This study uses multilevel modeling including state factors and allows a direct comparison of late-stage cancer rates across states. This more comprehensive multilevel analysis can help direct targeted resources at a national level toward those states exhibiting the worst rates of late-stage disease.

\section{Limitations}

There are several limitations for these analyses. First, the results pertain to the populations studied in the 11 SEER Registry Regions and cannot be generalized. In some cases, only partial states are covered by the Registries, and results cannot be generalized to the rest of these states. Next, because our data are not longitudinal, we cannot infer causal relationships. Third, because of restrictions in available data and constraints in computing capability, we use the county to reflect communities in our modeling, whereas smaller units or areas crossing county boundaries may be more appropriate for measuring preventive health markets. Fourth, the small sizes of minority populations with cancer within some states precluded separate analyses of Hispanic, Asian, or Native American subgroups, which were combined with 'other' races and ethnicities (which include persons of unknown race) in the modeling. In future, using a longer time span, more complete coverage of states and additional states in the analysis, it may be possible to look at these races and ethnicities in more detail. Finally, by using the linked SEER-Medicare data, persons with no sort of eligibility for Medicare or Medicaid are not included in the analysis. Thus privately insured or uninsured individuals are not included in our study. While the population aged $65+$ with cancer is well-represented in the SEER Registry regions, the population under age 65 is not well represented. Thus findings cannot be generalized and future studies using populationbased data are warranted.

\section{Summary and Conclusions}

In this paper, we use spatial analysis to answer questions related to both Why and Where disparities in late-stage BC and CRC diagnoses are observed. In answer to Why, we focus on state-level insurance factors and spatial interactions among the cancer population and 
their environment. Longer distances to closest provider of screening services are associated with significantly higher odds of late-stage diagnosis for both cancers, while living among persons of similar race or ethnicity seems to confer some protective effects for women with BC. Findings from these 11 states suggest that characteristics of state insurance environments may be significantly associated with cancer outcomes. We find that, ceteris paribus, as regards late stage $\mathrm{BC}$ the inpatient stay law seems to offer protective effects to women in segregated communities in the more racially mixed states that have passed this law. Significantly negative net effects of state law were predicted for CA (-0.07), GA $(-0.03)$, NJ (-0.01), and NM (-0.07). As regards late-stage CRC, we find that, ceteris paribus, the continuity of care law seems to offer protective effects to vulnerable cancer communities in the three states with the largest vulnerable population proportions. Significantly negative net effects of state law were predicted for CA $(-0.02)$, KY (-0.04), and LA (-0.06).

In answer to Where, the random intercepts estimator used here accounts for 'compositional' characteristics of people in counties to yield estimates of county-level rates of late stage BC or CRC diagnosis that are adjusted for sample selection as well as sample size. The predicted rates of late-stage diagnosis from the model are thus smoothed relative to the distribution of raw rates. The derived variances of the point estimates used to construct the confidence intervals are quite narrow in most cases (plot available from authors upon request). Using the estimates, we identified counties where the predicted rates of late-stage outcomes were in the upper and lower quadrants of the distribution, and using these produced maps showing the bivariate distribution of these predictions across both cancer types. Figures 2 and 3 demonstrate that some states have high risk for late-stage diagnoses in both cancers, while others seem to have problems with either BC or CRC.

This study uses population-based data, rather than survey sample data, to model actual disparities in the distributions of $\mathrm{BC}$ and $\mathrm{CRC}$ outcomes, namely the late-stage cancer at first cancer diagnosis. Although data were only available for 11 states, the findings still allow some generalizable findings. First, there is considerable heterogeneity across states, and across counties within states, in the rates of late-stage cancer diagnosed for these two cancer types. Second, the health insurance environment varies considerably across states, and variation in health insurance regulation and mandates is associated with cancer outcomes. Thus, a closer look at the state-level policy variables, preferably in a model that encompasses all 50 states, is warranted.

\section{Acknowledgments}

This work was supported by a National Cancer Institute grant (1R01CA126858-01A1) and an American Recovery and Reinvestment Act (ARRA) supplement to it. The content is solely the responsibility of the authors and does not necessarily represent the official views of RTI International, the University of North Carolina at Chapel Hill, the National Cancer Institute, or the National Institutes of Health.

\section{References}

Aday LA, Andersen R. A framework for the study of access to medical care. Health Services Research. 1974; 9:208-20. [PubMed: 4436074]

Administration on Aging. Federal interagency forum on aging-related statistics: older Americans update 2006: key indicators of well-being. United States Government Printing Office; Washington, DC: 2006.

America's Health Insurance Plans (AHIP). Low-income and minority beneficiaries in Medicare Advantage plans, 2002. AHIP Center for Policy and Research; 2005.

American Cancer Society (ACS). Cancer Facts and Figures 2010. American Cancer Society; Atlanta, GA: 2010. http://www.cancer.org/acs/groups/content/@epidemiologysurveilance/documents/ document/acspc-026238.pdf 
American Cancer Society (ACS). Cancer Prevention \& Early Detection Facts \& Figures 2011. American Cancer Society; Atlanta, GA: 2011. http://www.cancer.org/Research/CancerFactsFigures/ CancerPreventionEarlyDetectionFactsFigures/ACSPC-029459

Atherly, A.; Thorpe, KE. Emory University Rollins School of Public Health; Atlanta, GA: 2005. Value of Medicare Advantage to Low-Income and Minority Medicare Beneficiaries. Accessed online March 16 2011: c0540862.cdn.cloudfiles.rackspacecloud.com/Ken_Thorpe_MA_Report.pdf

Baker L. Managed Care Spillover Effects. Annual Review of Public Health. 2003; 24(1):435-456.

Bell JF, Zimmerman FJ, Almgren GR, et al. Birth outcomes among urban African-American women: a multivariate analysis of the role of racial residential segregation. Soc Sci Med. 2006; 63(12):30303045. [PubMed: 16997438]

Beyer KM, Rushton G. Mapping cancer for community engagement. Prev Chronic Dis. Jan.2009 6(1):A03. PMCID: PMC2644580. [PubMed: 19080009]

Congressional Budget Office (CBO). The price sensitivity of demand for nongroup health insurance. Background Paper. 2005. Available at/static/reportimages/ 79ABB18D6301D4D3C26BE05FFABD90EC.pdf

CDC. Centers for Disease Control and Prevention. Comprehensive Cancer Control Plans: A Content Review. 2005. Available online November 2011: http://www.cdc.gov/cancer/ncccp/pdf/ CCC_Plans_Content_Review.pdf

CDC. Centers for Disease Control and Prevention. Comprehensive cancer control: collaborating to conquer cancer, promotional toolkit. US Department of Health and Human Services; Atlanta (GA): 2006. (revised 2008)

Coughlin SS, Costanza ME, Fernandez ME, Glanz K, Lee JW, Smith SA, Stroud L, Tessaro I, Westfall JM, Weissfeld JL, Blumenthal DS. CDC-funded intervention research aimed at promoting colorectal cancer screening in communities. Cancer. 2006; 107(5 Suppl):1196-204. [PubMed: 16802326]

Cummins S, Curtis S, Diez-Roux A, Macintyre S. Understanding and representing 'place' in health research: A relational approach. Social Science and Medicine. Nov; 2007 65(9):1825-1838. [PubMed: 17706331]

Dai D. Black residential segregation, disparities in spatial access to health care facilities, and late-stage breast cancer diagnosis in metropolitan Detroit. Health \& Place. 2010; 16(6):1038-52. [PubMed: 20630792]

Gelman, A.; Hill, J. Data Analysis Using Regression and Multilevel/Hierarchical Models. Cambridge University Press; New York: 2007.

Given L, Black Bruce, Lowry Garry, Huang Philip, Kerner Jon. Collaborating to conquer cancer: a comprehensive approach to cancer control. Cancer Causes and Control. 2005; 16(Suppl. 1):3-14. [PubMed: 16208570]

Government Accountability Office (GAO). Use of Preventive Services Could Be Better Aligned with Clinical Recommendations. 2012. GAO-12-81, available online May 2012: http://www.gao.gov/ assets/590/587767.pdf

Haas JS, Earle CC, Orav JE, Brawarsky P, Neville BA, Williams DR. Racial segregation and disparities in cancer stage for seniors. Journal of General Internal Medicine. 2008; 23:699-705. [PubMed: 18338215]

Henley J, King J, German R, Richardson L, Plescia M. Surveillance of Screening-Detected Cancers (Colon and Rectum, Breast, and Cervix) - United States, 2004-2006. Morbidity and Mortality Weekly Report. Nov 26.2010 59(SS-9) available online at www.cdc.gov/mmwr.

Hetzel, L.; Smith, A. The 65 years and over population: 2000. United States Census Bureau; Washington, DC: 2001. census 2000 brief, C2KBR/01-10

Howlader, N.; Noone, AM.; Krapcho, M.; Neyman, N.; Aminou, R.; Waldron, W.; Altekruse, SF.; Kosary, CL.; Ruhl, J.; Tatalovich, Z.; Cho, H.; Mariotto, A.; Eisner, MP.; Lewis, DR.; Chen, HS.; Feuer, EJ.; Cronin, KA.; Edwards, BK., editors. SEER Cancer Statistics Review, 1975-2008. National Cancer Institute; Bethesda, MD: http://seer.cancer.gov/csr/1975_2008/, based on November 2010 SEER data submission, posted to the SEER web site, 2011. Available online April 2012: http://seer.cancer.gov/csr/1975_2008/index.html 
Jemal A, Siegel R, Ward E, Hao Y, Xu J, Thun M. Cancer statistics, 2009. CA: A Cancer Journal for Clinicians. 2009; 59:225-49. [PubMed: 19474385]

Kerner J, Andrews H, Zauber A. Geographically-based cancer control: methods for targeting and evaluating the impact of interventions on defined populations. J Clin Epidemiol. 1988; 41:543553. [PubMed: 3385456]

Khan AA, Bhardwaj SM. Access to health care: A conceptual framework and its relevance to health care planning. Evaluation \& the Health Professions. 1994; 17:60-76.

Komen Foundation Report, "Community Profile of Breast Cancer in Connecticut" The Connecticut Affiliate of Susan G. Komen for the Cure. 2011. available online March 2012: http:// www.komenct.org/ckfinder/userfiles/files/CT_Community_Profile_2011_Exec.pdf

Kowalski A, Congdon W, Showalter M. State health insurance regulations and the price of highdeductible policies. Forum for Health Economics \& Policy. 2008; 11(2) Available at http:// www.bepress.com/fhep/11/2/8.

Kramer M, Hogue C. Is Segregation Bad For Your Health? Epidemiologic Reviews. 2009; 31:178194. [PubMed: 19465747]

Kuo T, Mobley L, Anselin L. Geographic Disparities in Late-Stage Breast Cancer Diagnosis in California. Health\&Place. 2011; 17:327-334. [PubMed: 21144791]

LaPierre T, Conover C, Henderson J, Seward A, Taylor B. Estimating the Impact of State Health Insurance Mandates on Premium Costs in the Individual Market. Journal of Insurance Regulation. 2009; 27(3):3-36.

Laveist TA. The political empowerment and health-status of African-Americans-mapping a new territory. AJS. 1992; 97(4):1080-1095.

Laveist TA. Segregation, poverty, and empowerment: health consequences for African Americans. Milbank Q. 1993; 71(1):41-64. [PubMed: 8450822]

Luft HS. Assessing the evidence on HMO performance. Milbank Mem Fund Q Health Soc. 1980; 58:501-536. [PubMed: 6903797]

McLafferty S, Wang F. Rural Reversal? Rural-urban disparities in late-stage cancer risk in Illinois. Cancer. 2009; 115:2755-2764. [PubMed: 19434667]

MEDPAC. Dual eligible beneficiaries: An overview. Report to the Congress: New Approaches in Medicare. 2004 Chapter 3.

Meliker JR, Goovaerts P, Jacquez GM, AvRuskin GA, Copeland G. Breast and prostate cancer survival in Michigan: can geographic analyses assist in understanding racial disparities? Cancer. 2009; 115(10):2212-2221. [PubMed: 19365825]

Miller RH, Luft HS. Managed care plan performance since 1980: A literature analysis. JAMA. 1994; 271:1512-19. [PubMed: 8176832]

Mobley L, Kuo M, Clayton L, Evans D. Mammography facilities are accessible, so why is utilization so low? Cancer Causes and Control. 2009; 20(6):1017-1028. PMID: 19205911. [PubMed: 19205911]

Mobley L, Subramanian S, Koschinsky J, Frech HE, Clayton L, Anselin L. Managed care and the diffusion of endoscopy in fee-for-service Medicare. Health Services Research. 2011; 46(6):19051927. http://dx.doi.org/10.1111/j.1475-6773.2011.01301.x. [PubMed: 22092022]

1. Mobley L, Kuo T, Urato M, Subramanian S. Community contextual predictors of endoscopic colorectal cancer screening in the USA: spatial multilevel regression analysis. International Journal of Health Geographics. 2010; 9:44. open access available September 1, 2010: http://www.ijhealthgeographics.com/content/9/1/44. [PubMed: 20815882]

Mobley L, Kuo T, Driscoll D, Clayton L, Anselin L. Heterogeneity in mammography use across the nation: Separating evidence of disparities from the disproportionate effects of geography. International Journal of Health Geographics. 2008b; 7:32. [PubMed: 18590540]

Mobley LR, Kuo T, Andrews LS. How Sensitive are Multilevel Regression Findings to Defined Area of Context? A Case Study of Mammography Use in California. Medical Care Research and Review. Jun 1.2008a 65:315-337. PMID: 18259047. [PubMed: 18259047]

Mobley, L.; Frech, HE, III. Health Insurance: Designing Products to Reduce Costs.. In: Tremblay, V.; Tremblay, C., editors. Industry and Firm Studies. M.E. Sharpe; Armonk, NY: Feb. 2007 Chapter 6 
Naishadham D, Lansdorp-Vogelaar I, Siegel R, Cokkinides V, Jemal A. State disparities in colorectal cancer mortality patterns in the United States. Cancer Epidemiology, Biomarkers \& Prevention. 2011; 20(7):1296-302.

National Conference of State Legislatures (NCSL). Managed Care State Laws and Regulations, Including Consumer and Provider Protections. May. 2011 available online November 2011: , http://www.ncsl.org/default.aspx?tabid=14320

New MJ. The effect of state regulations on health insurance premiums: A revised analysis. 2006Available at http://s3.amazonaws.com/thf_media/2006/pdf/cda06-04.pdf

New Jersey Comprehensive Cancer Control Plan (2008-2012). available online march 2012: http:// www.nj.gov/health/ccp/ccc_plan/index.shtml

Oakes JM. The (mis)estimation of neighborhood effects: causal inference for a practicable social epidemiology. Social Science \& Medicine. 2004; 58:1929-1952. [PubMed: 15020009]

Osypuk T, Acevedo-Garcia D. Beyond individual neighborhoods: A geography of opportunity perspective for understanding racial/ethnic health disparities. Health\&Place. 2010 doi:10.1016/ j.healthplace.2010.07.002.

Parente, ST.; Feldman, R.; Abraham, J.; Xu, Y. Consumer response to a national marketplace for individual insurance. 2008. Final Technical Report for DHHS Contract HP-07-024. Available at http://www.hsinetwork.com/National_Marketplace_7-21-2008\%20FINAL_Blind.pdf

Probst J, Moore C, Glover S, Samuels M. Person and place: The compounding effects of race/ethnicity and rurality on health. American Journal of Public Health. Oct; 2004 94(10):1695-1703. [PubMed: 15451735]

Rabe-Hesketh, S.; Skrondal, A.; Pickles, A. GLLAMM Manual. U.C. Berkeley Division of Biostatistics Working Paper Series. Oct. 2004 Working Paper 160. http://www.bepress.com/ ucbbiostat/paper160

Rabe-Hesketh, S.; Skrondal, A. Multilevel and Longitudinal Modeling Using Stata. Second Edition. Stata Press; College Station, TX: 2008.

Roetzheim RG, Chirikos TN, Wells KJ, McCarthy EP, Ngo LH, Li D, Drews RE, Iezzoni LI. Managed care and cancer outcomes for Medicare beneficiaries with disabilities. Am J Manag Care. May; 2008 14(5):287-96. PubMed PMID: 18471033. [PubMed: 18471033]

Richardson L, Tai E, Rim S, Joseph D, Plescia M. Vital signs: Colorectal cancer screening, incidence, and mortality-United States, 2002-2010. Morbidity and Mortality Weekly Report. 2011; 60(26): 884-9. http://www.cdc.gov/mmwr/preview/mmwrhtml/mm6026a4.htm?s_cid=mm6026a4_w. [PubMed: 21734636]

Riley GF, Potosky AL, Lubitz JD, Brown ML. Stage of cancer at diagnosis for Medicare HMO and fee-for-service enrollees. American Journal of Public Health. Oct; 1994 84(10):1598-1604. doi: 10.2105/AJPH.84.10.1598. [PubMed: 7943477]

Riley GF, Potosky AL, Klabunde CN, Warren JL, Ballard-Barbash R. Stage at diagnosis and treatment patterns among older women with breast canceran hmo and fee-for-service comparison. JAMA. 1999; 281(8):720-726. [PubMed: 10052442]

Roche LM, Skinner RC, Weinstein RB. Use of a geographic information system to identify andf characterize areas with high proportions of distant stage breast cancer. J Public HealthManagement Practice. 2002; 8:26-32.

StataCorp. Stata Statistical Software: Release 12. StataCorp LP; College Station, TX: 2011.

Sullivan K. Managed care plan performance since 1980: another look at 2 literature reviews. Am J Public Health. Jul; 1999 89(7):1003-1008. 1999. [PubMed: 10394307]

Taplin S, Ichikawa L, Yood M, et al. Reason for late-stage breast cancer: absence of screening or detection, or breakdown in follow-up? J Natl Cancer Inst. Oct 20; 2004 96(20):1518-1527. 159. [PubMed: 15494602]

Wang F, McLafferty S, Escamilla V, Luo L. Late-stage breast cancer diagnosis and health care access in Illinois. The Professional Geographer. 2008; 60(1):54-69. [PubMed: 18458760]

Weil A, Tallon J. The States' Role in National Health Reform. J Law Med Ethics. 2008; 36(4):690692. Winter. [PubMed: 19093992]

Williams DR, Collins C. Racial residential segregation: A fundamental cause of racial disparities in health. Public Health Reports. 2001; 116(5):404-416. [PubMed: 12042604] 
Wolinsky FD. The performance of health maintenance organizations: an analytic review. Milbank Mem Fund Q Health Soc. 1980; 58:537-587. [PubMed: 7001268]

Wolter, KM. Introduction to Variance Estimation. Second Edition.. Springer, Inc.; 2007. 


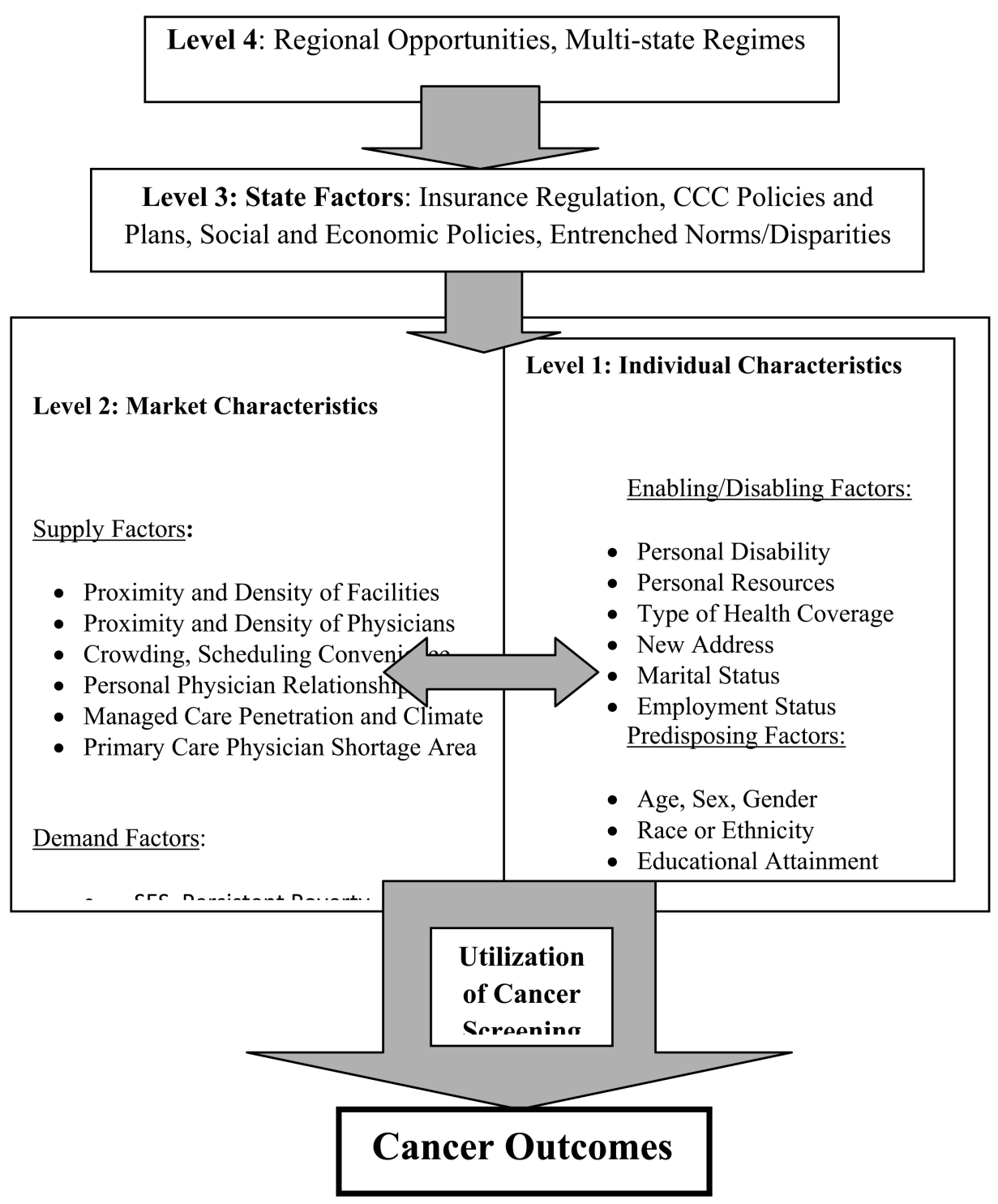

Figure 1.

Spatial Interaction Model of Cancer Prevention and Outcomes 

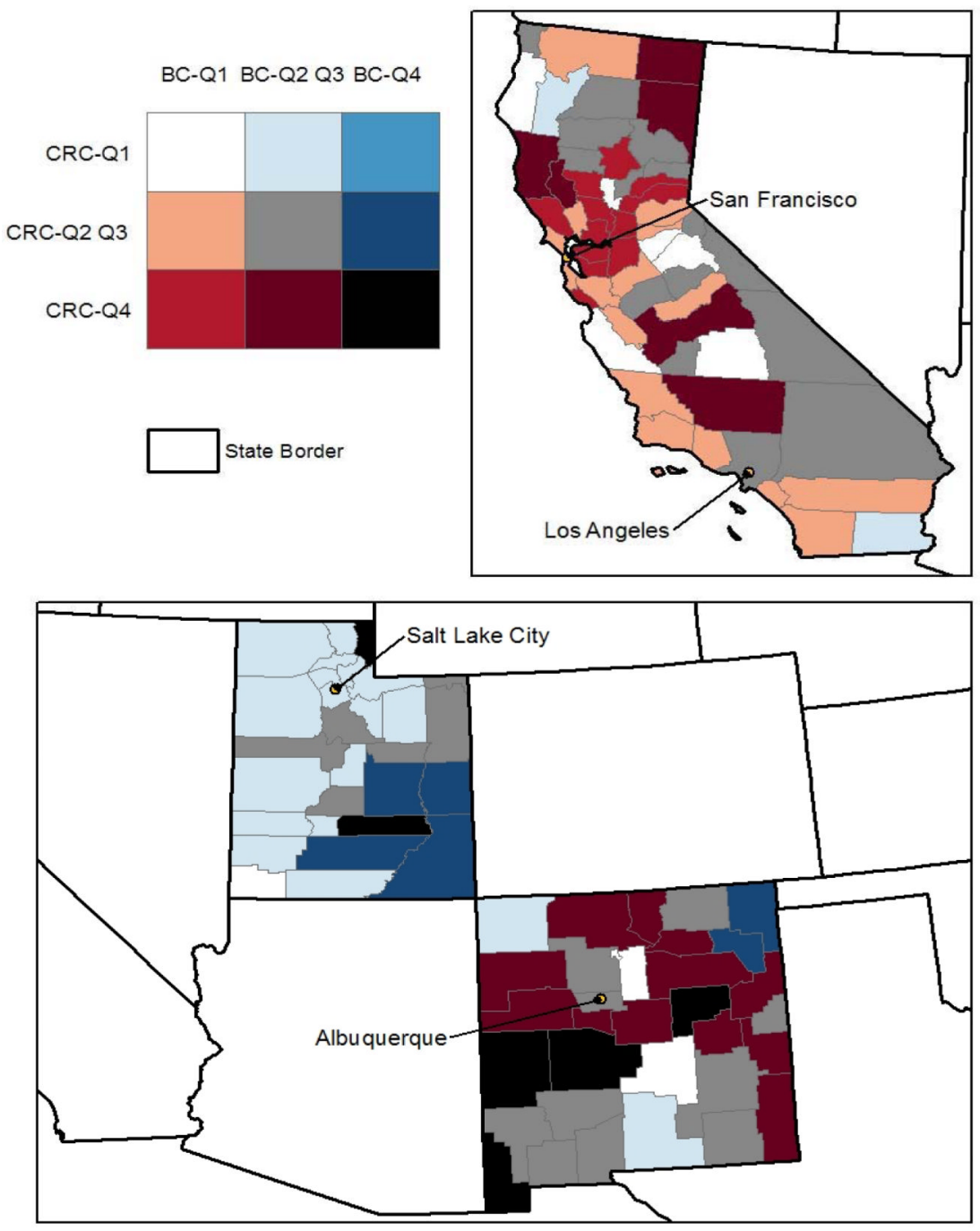

Figure 2. Predicted County Rates of Late-Stage BC and CRC in California, Utah, and New Mexico

The counties colored black, bright red, bright blue, and white (the four corners of the bivariate legend) are of most interest. Counties colored white have predicted rates of late stage BC and CRC (both) in the lower quartile (Q1) of the distribution across all counties in the 11 states. On the other extreme, counties colored black have predicted late-stage cancer rates for both cancer types that are in the upper quartile (Q4) of the distribution. The bright red color indicates that $\mathrm{BC}$ rates are in the lower quartile while $\mathrm{CRC}$ rates are in the upper quartile, while the bright blue color indicates that $\mathrm{BC}$ rates are in the upper quartile while $\mathrm{CRC}$ rates are in the lower quartile. Generally, the red colors signal concerns for CRC while the blue colors signal concerns for BC. 

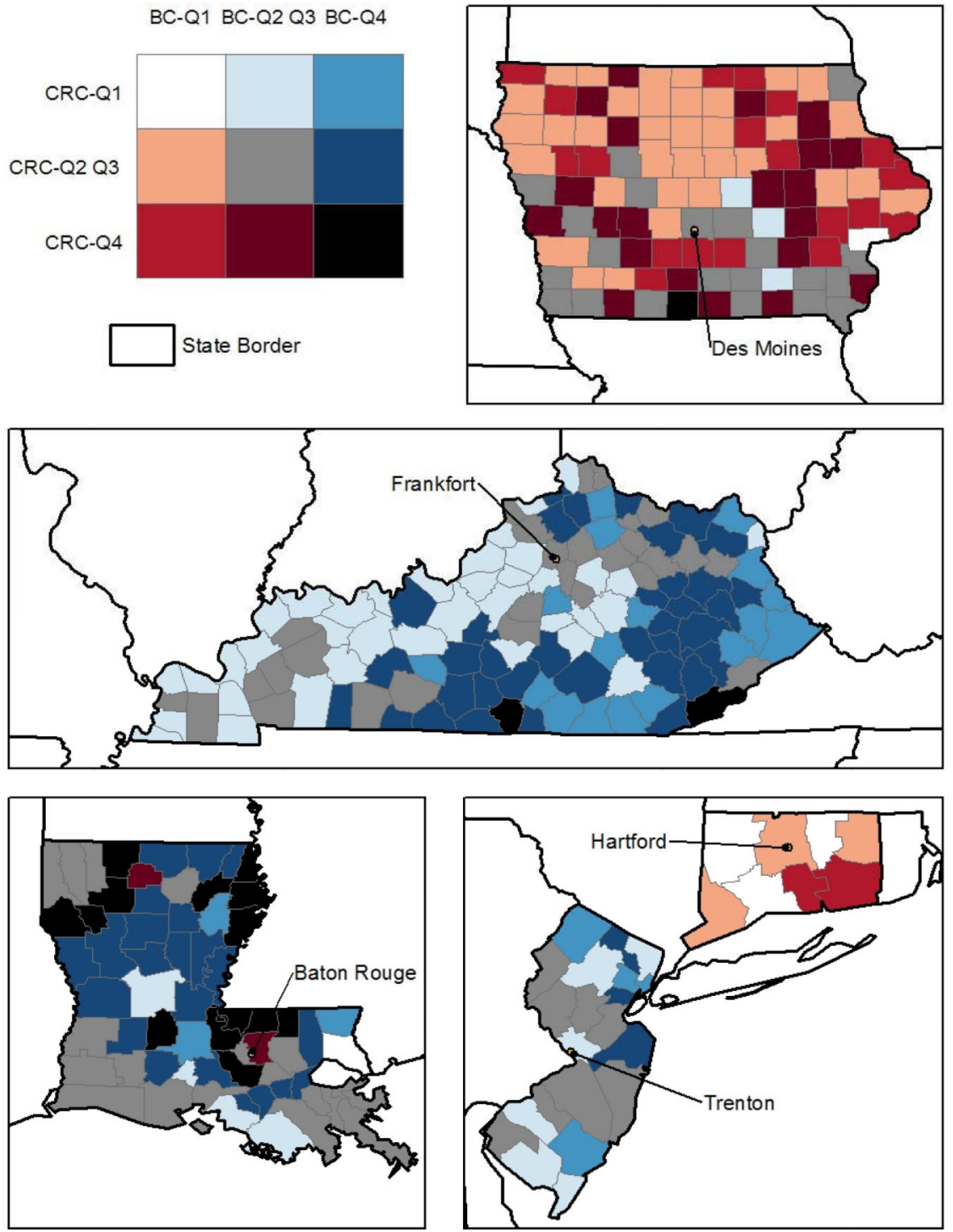

Figure 3. Predicted County Rates of Late-Stage BC and CRC in Iowa, Kentucky, Louisiana, Connecticut, and New Jersey

The counties colored black, bright red, bright blue, and white (the four corners of the bivariate legend) are of most interest. Counties colored white have predicted rates of late stage BC and CRC (both) in the lower quartile (Q1) of the distribution across all counties in the 11 states. On the other extreme, counties colored black have predicted late-stage cancer rates for both cancer types that are in the upper quartile (Q4) of the distribution. The bright red color indicates that $\mathrm{BC}$ rates are in the lower quartile while $\mathrm{CRC}$ rates are in the upper quartile, while the bright blue color indicates that $\mathrm{BC}$ rates are in the upper quartile while $\mathrm{CRC}$ rates are in the lower quartile. Generally, the red colors signal concerns for CRC while the blue colors signal concerns for BC. 


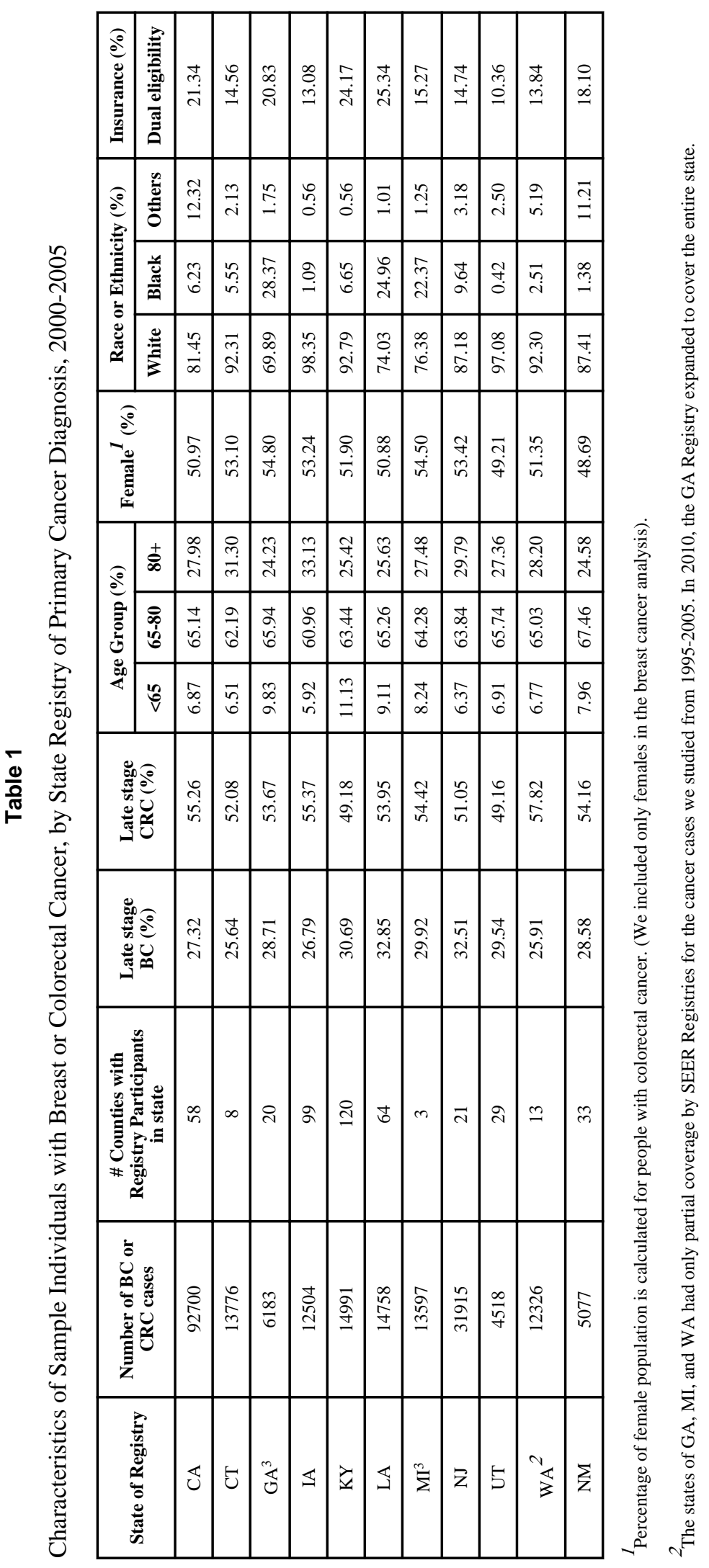




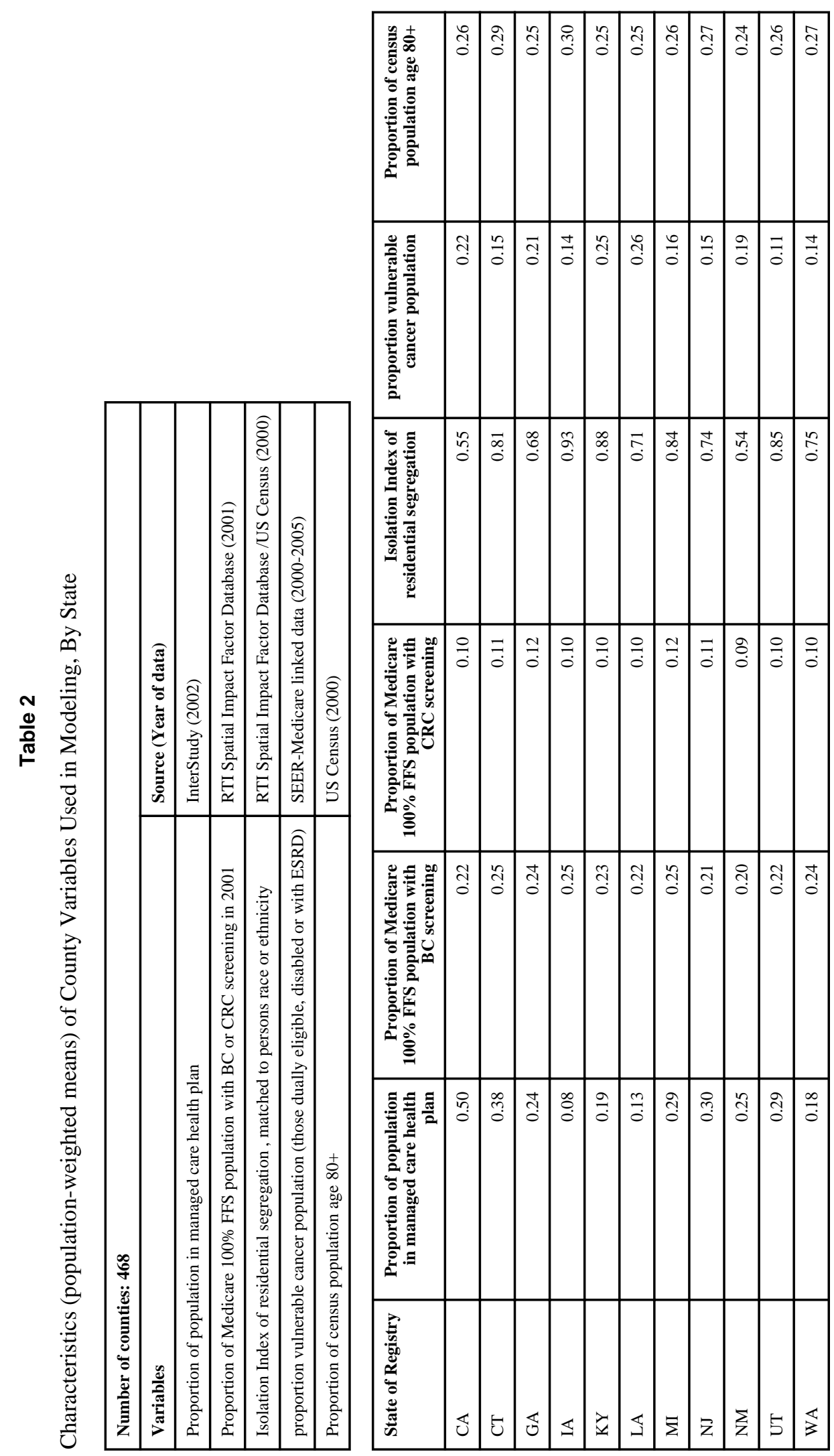




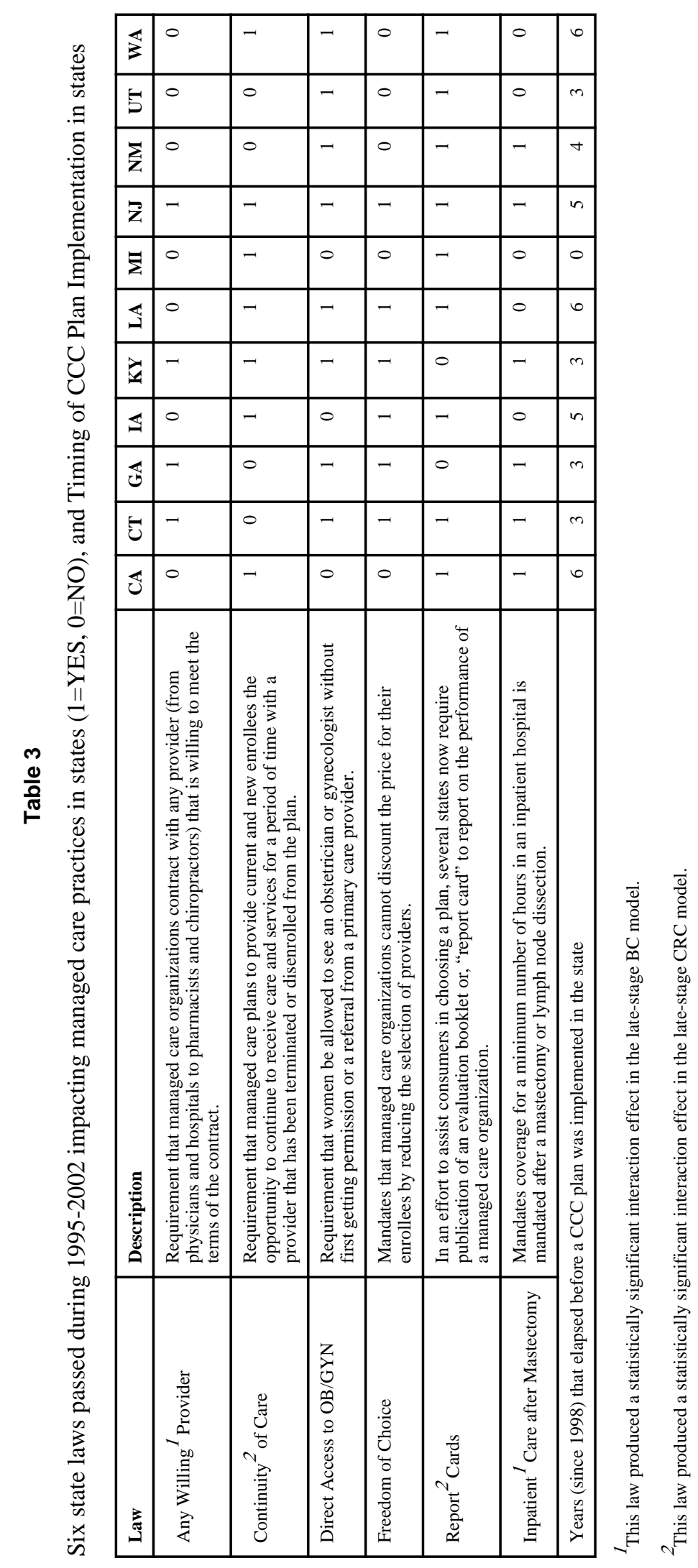

Health Place. Author manuscript; available in PMC 2013 September 01. 
Table 4

Comparison of Two State Insurance Variable Models for Late Stage CRC

\begin{tabular}{|c|c|c|c|c|}
\hline \multirow{2}{*}{$\begin{array}{l}\text { Outcome: whether person was diagnosed with late stage colorectal cancer } \\
\text { during 2000-2005. } \\
\text { Covariate }\end{array}$} & \multicolumn{2}{|c|}{ state law: continuity of care } & \multicolumn{2}{|c|}{ state law: plan report carc } \\
\hline & Coeff & P-val & Coeff & P-val \\
\hline \multicolumn{5}{|l|}{ Person level variables } \\
\hline female (versus male) & 0.042 & 0.001 & 0.042 & 0.001 \\
\hline under age 65 category (versus $80+$ ) & -0.062 & 0.028 & -0.062 & 0.027 \\
\hline age65-79 category (versus $80+$ ) & -0.043 & 0.002 & -0.043 & 0.002 \\
\hline married & -0.080 & 0.000 & -0.081 & 0.000 \\
\hline Black (versus white) & 0.125 & 0.000 & 0.127 & 0.000 \\
\hline any other race or ethnicity (versus white) & 0.062 & 0.013 & 0.063 & 0.011 \\
\hline Distance to closest endoscopy provider & 0.004 & 0.005 & 0.005 & 0.004 \\
\hline \multicolumn{5}{|c|}{ County level variables } \\
\hline proportion population in managed care health plans & 0.324 & 0.000 & 0.303 & 0.000 \\
\hline proportion Medicare FFS population with CRC screening & -0.012 & 0.134 & -0.012 & 0.152 \\
\hline$\gamma_{2:}$ proportion vulnerable cancer population (dual, disabled, ESRD) & 1.090 & 0.018 & 0.846 & 0.004 \\
\hline proportion of census population age $80+$ & 0.567 & 0.262 & 0.621 & 0.193 \\
\hline \multicolumn{5}{|c|}{ State level variables } \\
\hline Years that elapsed before a CCC plan was implemented in state & 0.021 & 0.254 & 0.033 & 0.004 \\
\hline$\gamma_{3:}$ regulation requiring state law or mandate (see column headings) & 0.192 & 0.071 & 0.320 & 0.001 \\
\hline \multicolumn{5}{|c|}{ Cross-level interaction } \\
\hline$\gamma_{4}:$ Interaction of vulnerable county proportion and state law or & -0.961 & 0.005 & -0.976 & 0.006 \\
\hline Goodness of Fit (AIC) & \multicolumn{2}{|c|}{146153.0} & \multicolumn{2}{|c|}{146149.2} \\
\hline
\end{tabular}

Goodness of Fit provided by re-estimation using SAS GLIMMX procedure 
Table 5

Comparison of Two State Insurance Variable Models for Late Stage BC

\begin{tabular}{|c|c|c|c|c|}
\hline \multirow{2}{*}{$\begin{array}{l}\text { Outcome: whether the person diagnosed with late stage BC } \\
\text { during 2000-2005. } \\
\text { Covariate }\end{array}$} & \multicolumn{2}{|c|}{$\begin{array}{l}\text { State law: allow inpatient stay } \\
\text { following mastectomy }\end{array}$} & \multicolumn{2}{|c|}{ State Law: any willing provider } \\
\hline & Coeff & P-val & Coeff & P-val \\
\hline \multicolumn{5}{|l|}{ Person level } \\
\hline $\begin{array}{l}\text { Person is dually eligible and/or has disability or end-stage renal } \\
\text { disease }\end{array}$ & 0.344 & 0.000 & 0.345 & 0.000 \\
\hline person is in the under age 65 category (versus $80+$ ) & -0.114 & 0.000 & -0.115 & 0.000 \\
\hline person is in the age 65-79 category (versus $80+$ ) & -0.129 & 0.000 & -0.129 & 0.000 \\
\hline person is married & -0.119 & 0.000 & -0.119 & 0.000 \\
\hline person is Black (versus white) & 0.229 & 0.000 & 0.225 & 0.000 \\
\hline person is any other race or ethnicity (versus white) & -0.065 & 0.089 & -0.090 & 0.020 \\
\hline Distance to closest mammography provider & 0.003 & 0.073 & 0.003 & 0.061 \\
\hline \multicolumn{5}{|l|}{ County level } \\
\hline proportion of population in managed care health plans & -0.127 & 0.074 & -0.162 & 0.017 \\
\hline proportion FFS population with BC screening & -0.019 & 0.000 & -0.017 & 0.000 \\
\hline $\boldsymbol{\gamma}_{2:}$ Isolation index of residential segregation: social support & -0.257 & 0.007 & -0.107 & 0.123 \\
\hline \multicolumn{5}{|l|}{ State level } \\
\hline $\begin{array}{l}\boldsymbol{\gamma}_{3} \text { : regulation requiring state insurance law or mandate (see } \\
\text { column headings) }\end{array}$ & -0.251 & 0.004 & -0.035 & 0.664 \\
\hline \multicolumn{5}{|l|}{ Cross-level interaction } \\
\hline$\gamma_{4:}$ Interaction of social support and state insurance variable & 0.311 & 0.002 & 0.220 & 0.019 \\
\hline Goodness of Fit (AIC) ${ }^{*}$ & \multicolumn{2}{|c|}{137839.6} & \multicolumn{2}{|c|}{137843.4} \\
\hline
\end{tabular}

